\title{
Development of clinical pathways for long-acting reversible contraceptives (LARCs)
}

\section{Pauline Allen}

\section{Why was the change needed?}

Long-acting reversible contraceptives (LARCs) are underused and many health professionals do not feel confident about how best to provide them. In 2003, Gloucestershire Sexual Health Services were successful in bidding for a programme for the National Primary Care Contracting Collaborative. This was to improve the provision for LARCs, develop user-friendly sexual health services, and ensure easy access to a full choice of providers.

\section{Who was involved in the development?}

Our team consisted of a Primary Care Trust project lead and manager, two consultants and representatives from Contraception and Sexual Health (C\&SH), Genitourinary Medicine, and from three participating general practices. It included representatives of the Local Pharmaceutical Committee, Teenage Pregnancy Unit, the Patient and Public Involvement Forum, and Public Health. We wanted to pilot and develop new ways of delivering sexual health services, using tested change management methods, and eventually to work with other Trusts across the county to identify best practice models.

\section{What change method was used?}

The change management method 'Plan, Do, Study, Act' (PDSA), Shewhart's cycle, can be found in detail on many websites ${ }^{1}$ but briefly consists of:

1 Plan what you are going to do, after you have gathered some evidence of the nature and size of the problem.

2 Do it, preferably on a small scale first.

3 Study the results. Did the plan work?

4 Act on the results. If the plan was successful, standardise this new way of working. If it was not, try something else.

Keep the steps small at the start and gather the evidence rapidly. This makes change manageable and motivating for the team. We started off with simple questions such as:

1 Are copper intrauterine devices (IUDs) being offered for postcoital contraception at the same time as emergency hormonal contraception (EHC)? No, they were not, because it was too difficult to arrange immediate IUD fittings in general practice. The teams learnt about giving EHC and booking an appointment

J Fam Plann Reprod Health Care 2008; 34(2): 128

Gloucestershire Primary Care Trust, Department of Contraception and Sexual Health, Gloucestershire Royal Hospital, Gloucester, UK

Pauline Allen, FFSRH, Consultant in Family Planning, Reproductive Health and Psychosexual Medicine

Correspondence to: Dr Pauline Allen, Contraception and Sexual Health, Hope House, Gloucestershire Royal Hospital, Great Western Road, Gloucester GL1 3NN, UK.

E-mail: Pauline.Allen@glos.nhs.uk for IUD fitting within a few days (up to Day 19). We repeated the information gathering to establish what had changed.

2 How many women attending the Pregnancy Advisory Service (PAS) had failed EHC?

We did several small PDSA cycles linking the findings to the questions. Improvements resulted from working across all the sexual health services (e.g. a reduction in the percentage of failed EHC at PAS) but we needed more specific audit and training programmes to ensure ongoing learning.

\section{An example of effective change}

General practitioners (GPs) wanted to improve their expertise with intrauterine methods. We introduced 'IUD/IUS Masterclasses' - half-day workshops for 12 experienced GPs with two experts in C\&SH and gynaecology - and 96 doctors attended over a 2-year period. A follow-up questionnaire with these GPs indicated most were now managing problems much more effectively within their own practices. There was still a need for experienced help with more complex problems or gaps in their service, not just with the IUD/IUS methods but with all LARCs. We developed clinical pathways to address this need for the whole county, helped by the National Institute for Health and Clinical Excellence (NICE) Clinical Guideline 30 for LARCs. ${ }^{2}$

Meetings, discussions and e-mails took place between those working in $\mathrm{C} \& \mathrm{SH}$, gynaecology and primary care. The pathways were first piloted and then the final document, printed in colour, was sent to every GP in the county. A planned countywide audit, which received an $84 \%$ response rate, was carried out 3 months later to identify gaps in LARC provision and further training needs.

The pathways are now available on a public website and will be linked in 2008 into other clinical pathways across our local clinical network. They can be accessed on the Gloucestershire Sexual Health Services website. ${ }^{3}$

\section{Acknowledgements}

Gloucestershire Sexual Health Service would like acknowledge help received from Schering and Organon with original discussions and from Organon for printing the Clinical Pathways for GPs.

\section{Author note}

This article was written by the author on behalf of the Sexual Health Service, Gloucestershire Primary Care Trust, UK.

\section{References}

1 Institute for Health Improvement, Boston, MA, USA. http://www.ihi.org/lHI/Topics/Improvement/ImprovementMetho ds/Tools/Plan-Do-Study-Act+(PDSA)+Worksheet.htm [Accessed 13 February 2008].

2 National Institute for Health and Clinical Excellence (NICE). Long-acting Reversible Contraception (Clinical Guideline 30). 2005. http://www.nice.org.uk/nicemedia/pdf/CG030 fullguideline.pdf [Accessed 13 February 2008].

3 Sexual Health in Gloucestershire. www.sexhelpglos.nhs.uk (follow the link to Gloucestershire Sexual Health Services).

\section{Visit the Faculty Website at www.fsrh.org}

